\title{
Geração de conhecimento na área da saúde humana: uma análise da interação universidade-organizações no Rio Grande do Sul
}

Ana Lúcia Tatsch* (D)

Marisa dos Reis A. Botelho** (D)

Janaina Ruffoni ${ }^{* * *}$

Lara Stumpf Horn****

* Universidade Federal do Rio Grande do Sul (UFRGS), Porto Alegre (RS), Brasil. E-mail: analuciatatsch@gmail.com

** Universidade Federal de Uberlândia (UFU), Uberlândia (MG), Brasil. E-mail: botelhomr@ufu.br

*** Universidade do Vale do Rio dos Sinos (Unisinos), Porto Alegre (RS), Brasil. E-mail: janainart@gmail.com

**** Universidade Federal do Rio Grande do Sul (UFRGS), Porto Alegre (RS), Brasil. E-mail: lara_horn@hotmail.com

\section{Resumo}

Este trabalho contribui para a caracterização dos processos de geração de conhecimento e inovação na área da saúde humana em países emergentes, como o Brasil. O objetivo é examinar as interações estabelecidas entre as universidades, a partir de seus grupos de pesquisa, e outras organizaçóes. Realizou-se uma pesquisa exploratória junto a cinco grupos de pesquisa da Universidade Federal do Rio Grande do Sul. Dados secundários a respeito dos grupos de pesquisa foram também utilizados. Conclui-se que equipes multidisciplinares de pesquisadores qualificam o processo de geração de conhecimento e inovaçóes; hospital-escola é ator-chave; pacientes são relevantes no estabelecimento de interaçóes e construção de conhecimento pelos grupos; outros pesquisadores de centros de pesquisa ou universidades do Brasil e do exterior 
participam do processo de geração de conhecimento; empresas industriais têm pouca ou nenhuma presença nas interaçóes estabelecidas; existe desconexão entre produção científica e tecnológica. Essas características corroboram outros achados já divulgados na literatura acadêmica.

Palavras-chave | Sistema de Inovação em Saúde; Universidade-Organizaçôes; Hospitais Universitários; Interaçôes entre Agentes; Rio Grande do Sul

Códigos-JEL | I15; O14; O30

\title{
Generation of knowledge in the area of human health: an analysis of university-organizations interaction in Rio Grande do Sul
}

\begin{abstract}
This paper aims to contribute to the characterization of processes that generate knowledge and innovation in the health sector in emerging countries, such as Brazil. In order to do so, the interactions of five research groups from the Federal University of Rio Grande do Sul were analyzed. In addition to the field research the study was based on secondary data. This exploratory study identified important characteristics of the interactions: multidisciplinary researcher teams qualify the process of generating knowledge and innovations; the teaching hospital is the key actor; patients are relevant in the establishment of interactions and generation of knowledge by the groups, whereas clinical research constitutes an important way of creating new ideas; other researchers in Brazil and abroad participate in the process of generating knowledge; there is a disconnection between scientific and technological production. These characteristics corroborate at large other findings that have been already published in specialized literature.
\end{abstract}

Keywords | Health Innovation System; University-Organizations Collaboration; University Hospitals; Interaction Networks; Rio Grande do Sul

JEL Codes | I15; O14; O30 


\section{Introdução}

A área de saúde humana é objeto privilegiado nas discussōes sobre desenvolvimento econômico. Políticas públicas de diversos países têm direcionado recursos para essa área. $\mathrm{O}$ alcance de maiores níveis de bem-estar social nos países em desenvolvimento, como sugere Albuquerque (2009), associa-se a melhorias no sistema de inovação orientadas pela solução de problemas típicos dessas regiôes. Logo, as especificidades do seu progresso científico-tecnológico merecem ser pesquisadas (ALBUQUERQUE; CASSIOLATO, 2002).

Estudos acadêmicos têm destacado a relevância do referencial teórico neoschumpeteriano de sistemas de inovação para analisar a complexidade que caracteriza as inovaçôes voltadas à saúde. Corroboram para isso o caráter interdisciplinar associado ao conhecimento nessa área, a importância dos serviços médicos e hospitalares como agentes proativos na inovação, o papel de diferentes atores na geração de conhecimento e a relevância dos hospitais como ambientes de seleção e geração de inovaçóes.

Considerando o exposto, a pergunta de pesquisa é: quais características apresentam as interaçóes entre universidades e outras organizaçóes com vistas à geraçáo de conhecimentos e à inovação em assistência médica, produtos e/ou processos na área da saúde humana?

O objetivo é analisar as interaçóes estabelecidas entre as universidades, a partir de seus grupos de pesquisa, e outras organizaçôes, ${ }^{1}$ particularmente os hospitais, mas também empresas industriais, visando o desenvolvimento de produtos e/ou processos inovadores para a área da saúde humana e avanços nos serviços médicos. Este tema é ainda pouco estudado para os países em desenvolvimento.

Adotou-se a estratégia de analisar casos de grupos de pesquisa de excelência que realizam, ao longo do tempo, interaçôes com outras organizaçóes (hospitais, empresas, etc.). A escolha por esse procedimento justifica-se pela necessidade de aprofundar o conhecimento a respeito de atores relevantes dos sistemas de inovaçáo. Foram examinadas as interaçōes de cinco grupos de pesquisa da Universidade Federal do Rio Grande do Sul (UFRGS). ${ }^{2}$ A seleçấo foi baseada tanto nas informaçóes

1 Cabe esclarecer que o termo "universidade-empresa", comumente usado na literatura, está sendo aqui substituído por "universidade-organizaçôes”, uma vez que a área da saúde exige um olhar mais amplo em função de suas múltiplas interaçōes. Soma-se a isso o fato de a base consultada para coleta de dados secundários empregar o termo "empresa" não no sentido estrito de firma, mas sim como "organizaçôes de modo geral": universidades, prefeituras, associaçôes, hospitais e outros grupos de pesquisa.

2 Universidade pública de longa tradiçấo e importante ator no sistema de conhecimento e inovaçăo brasileiro. Considerando suas interaçôes, a UFRGS já foi apontada como gatekeeper no processo de busca e transmissão de conhecimentos (COSTA; RUFFONI; PUFFAL, 2011). 
coletadas junto ao Diretório de Grupos de Pesquisa (DGP) do Conselho Nacional de Desenvolvimento Científico e Tecnológico (CNPq) quanto nos resultados do trabalho de Tatsch, Ruffoni e Botelho (2016), que indicam os grupos de pesquisa da UFRGS atuantes no âmbito da saúde humana que mais estabelecem interaçôes com organizaçóes em sentido largo. A partir de um roteiro de questôes, realizaram-se entrevistas em profundidade com os líderes desses grupos.

A seguir, é sintetizado o referencial teórico. Posteriormente, são descritos os procedimentos metodológicos e discutidos os resultados da pesquisa empírica. Por fim, são feitas as consideraçôes finais.

\section{Referencial teórico}

A literatura neoschumpeteriana concebe a inovação como um fenômeno sistêmico, fruto essencialmente das diversas interaçóes que as organizaçóes estabelecem no ambiente em que atuam. Os avanços nessa literatura levaram à construção do enfoque de sistemas de inovação nos seus vários âmbitos de análise: nacionais (FREEMAN, 1995; LUNDVALL, 1988; 1992; NELSON, 1993), regionais (COOKE, 1998; ASHEIM; GERTLER, 2006) e setoriais (MALERBA, 2002). Em todos eles, a análise das interaçóes que produzem o conhecimento e a inovação é central (LUNDVALL, 1988; 1992).

Mowery e Sampat (2006, p. 221), ao sintetizarem os resultados das diversas contribuiçóes destes enfoques, indicam que "research collaboration beetween universities and industry is growing throughout the industrial economies, in university systems with very different structures".

Nos setores intensivos em ciência, as interações entre empresas e universidades e/ou centros de pesquisa são fundamentais. Destaca-se, nas abordagens teóricas sobre a relação universidade-empresa, a relevância dos insumos de conhecimento para a pesquisa científica, em seus aspectos de escala e diversidade, assim como a interdisciplinaridade e as colaboraçóes entre diversos atores, em nível nacional ou internacional, como requisitos fundamentais para a pesquisa científica e inovação (MOWERY; SAMPAT, 2006).

Entre os setores intensivos em conhecimento científico, figuram o farmacêutico e parte importante da indústria de máquinas e equipamentos para a área da saúde humana. Estas indústrias interagem frequentemente com os hospitais, especialmente com os universitários, loci de pesquisas na área médica. Diversos fluxos de aprendizado e conhecimento operam dos hospitais universitários para a indústria e em 
sentido contrário, em fluxos bidirecionais, em que a complexidade das interaçóes e as mudanças não determinísticas constituem um processo evolucionário (NELSON; WINTER, 1982; NELSON et al., 2011).

Gelijns e Rosemberg (1994) destacam, de forma pioneira, a grande complexidade por trás da mudança tecnológica em produtos e serviços médicos e, portanto, a necessidade de considerar os vários tipos de interaçôes que suportam o processo inovativo. Consoli e Mina (2009) argumentam que as atividades são fortemente influenciadas por fatores organizacionais, estratégicos e relacionais, que fogem aos arquétipos de inovação de produto ou processo.

Tomando como referência desenvolvimentos específicos nessa área, diversos trabalhos destacam, com diferentes metodologias de pesquisa, a natureza evolucionária da pesquisa e inovação no campo da saúde humana. Metcalfe, James e Mina (2005) discutem o desenvolvimento, no campo da oftalmologia, de lentes intraoculares para a correção da catarata. Também no campo da oftalmologia, tratamentos para a correção de glaucoma, assim como os de doenças coronarianas, são abordados por Consoli e Mina (2009).

Esses e outros trabalhos dedicam particular atenção aos serviços médicos como fundamentais no processo inovativo. Estabelece-se um tipo específico de relação produtor-usuário (LUNDVALL, 1988; HICKS; KATZ, 1996; ALBUQUERQUE; CASSIOLATO, 2002), em que se põe em relevo o papel dos serviços, especialmente os oriundos de hospitais universitários. Esse é o foco de Djellal e Gallouj (2005) e de Windrum e García-Goñi (2008) quando mostram que os hospitais que abrigam tratamentos de alta complexidade e/ou pesquisas na área da saúde humana interagem frequentemente com a indústria de fármacos e medicamentos e a de máquinas e equipamentos médicos.

Um contexto tipicamente evolucionário se apresenta quando os mecanismos de aprendizagem, especialmente nas fases de testes clínicos, envolvem um conjunto de adaptaçốes necessárias para o êxito das inovaçóes (NELSON et al., 2011). Ou seja, há mecanismos de learning by doing e learning by using que são fundamentais para que invençóes, frequentemente desenvolvidas em laboratórios universitários, se transformem em inovaçóes médicas.

Metcalfe, James e Mina (2005, p. 1283) destacam:

[...] innovation in medicine is a process that is distributed across time, space and epistemic and institutional domains; that it entails the entrepreneurial effort of creative individuals as well as the emergence of correlated understanding among 
heterogeneous agents whose rules of interaction are contingently instituted in socio-economic systems along unfolding scientific and technological trajectories.

Thune e Mina (2016) reforçam o entendimento dos hospitais como atores centrais, informando as funçôes dessas instituições no sistema de inovação em saúde: grandes provedores de serviços de saúde; usuários de novas tecnologias, gerando uma demanda externa por inovação; e potenciais desenvolvedores de processos de inovaçōes organizacionais. Além disso, os hospitais, enquanto parte do sistema educacional, são espaço de treinamento de novos profissionais e podem, ainda, ser loci de experimentação clínica e instituiçôes de P\&D. Para os autores, os hospitais no geral, mas particularmente os hospitais-escola, tornam-se os nódulos centrais nas redes de saúde na medida em que executam esses vários papeis. Especialmente, os hospitais universitários funcionam como intermediários entre diferentes domínios e fontes de conhecimento, como o científico, o clínico, o técnico e o comercial. São também pontes entre os diferentes modos de aprendizado (por meio da prática médica, pesquisa básica e aplicada). Ligam ainda os sistemas de saúde nas diferentes fases do processo de inovação, pois podem estar envolvidos na geração de ideias, na fase de verificação ou de testes, na implementação e na difusão.

Dado o papel central dos hospitais, especialmente os universitários, como ambientes de geração e seleção de inovaçóes, torna-se necessário, seguindo os argumentos de Thune e Mina (2016), um aprofundamento nas pesquisas. Acrescenta-se ainda, como outra justificativa para o presente trabalho, a escassez de estudos que se dedicam a esta temática para o caso brasileiro. Pesquisas desta natureza são de suma importância para que se possa promover sistemas de inovação em saúde que tenham como referência as especificidades dos países em desenvolvimento.

\section{Procedimentos metodológicos}

Este estudo parte do exame dos dados coletados junto ao DGP/CNPq. Com base nestas informaçóes e nos resultados do trabalho de Tatsch, Ruffoni e Botelho (2016), os grupos de pesquisa a serem investigados foram selecionados, ${ }^{3}$ adotando-se os seguintes procedimentos:

3 É importante atentar para a conclusão do trabalho de Silva Neto et. al. (2012). Conforme comprovam esses autores, o DGP subestima as interaçôes na área de conhecimento da saúde. Esclarecem que o tipo de conexấo existente entre universidades, institutos de pesquisa, hospitais, clínicas e centros médicos não está sendo devidamente capturado, pois os líderes dos grupos de pesquisa podem considerar que estas instituiçôes nẫo são empresas. Ainda assim, o DGP é a única base de dados oficial disponível, com série histórica, que informa características dos grupos de pesquisa no Brasil. 
- os dados de dois Censos do DPG - 2010 e 2016 - foram levados em conta. Consideraram-se os grupos da grande área das Ciências da Saúde no Rio Grande do Sul (RS) que apresentaram interaçóes com organizaçóes em sentido amplo para a seleção de grupos com uma prática contínua de interação;

- foram identificados 20 grupos. Dois estavam inativos e 18 líderes de grupos foram contatados e convidados a participar do estudo;

- o número de grupos convidados foi ampliado a partir da sugestáo de um dos entrevistados. Dada a relevância do desempenho destes grupos no que diz respeito à produção intelectual dos seus membros e às interaçóes que estabelecem com hospitais, optou-se por incluí-los na amostra. Essa é a situação dos grupos D e E;

- foi possível realizar entrevistas com cinco líderes de diferentes grupos de pesquisa;

- as entrevistas em profundidade ocorreram no início de 2017, com duração de uma a três horas, sendo gravadas, transcritas e analisadas.

Os cinco grupos estáo indicados no estudo por letras - A, B, C, D e E - e são caracterizados na próxima seção.

\section{Descrição dos grupos e discussão dos resultados}

O grupo A foi formado em 2003 e atua na área de Medicina, sendo liderado, desde a sua instalação, por professor com formação, em todos os níveis, no campo da Medicina. As linhas de pesquisa do grupo relacionam-se ao transtorno de déficit de atenção com hiperatividade (TDAH). Em 2004, primeiro ano de participação no Censo do DGP, o grupo contava com 30 membros, sendo cinco pesquisadores, 16 estudantes e nove técnicos.

Em 2016, já eram 68 participantes, sendo 25 pesquisadores, 42 estudantes e um técnico. O grupo possui um histórico de interação com empresas privadas, especialmente as atuantes na área farmacêutica, todas com remuneraçáo do tipo financeira e envolvendo relacionamentos de consultoria técnica e pesquisa científica sem consideraçôes de uso imediato dos resultados. A produção bibliográfica do grupo é bastante expressiva. Detém propriedade intelectual de software criado em parceria com empresas privadas. 
O grupo B foi instaurado em 2005 e tem como área predominante a Saúde Coletiva. É liderado por dois professores, um com formação em Educação Física ${ }^{4}$ e outro formado na área de Engenharia Elétrica e Engenharia de Materiais. As linhas de pesquisa do grupo incluem biomecânica hospitalar; desenvolvimento e aplicação de técnicas de neuromodulação em reabilitação; tecnologias assistivas para tratamento de adultos críticos, da incontinência urinária em mulheres e da osteoartrite. Em 2016, o grupo era composto por 24 participantes, sendo 13 estudantes e 11 pesquisadores. As interaçóes do grupo, todas classificadas como relacionamentos de pesquisa científica, se dâo com instituiçóes de educação superior e hospitais e não possuem transferências de recursos de qualquer espécie. Este grupo possui nove patentes depositadas. ${ }^{5}$

O grupo de pesquisa C foi formado em 2007 sob a liderança de professor com formação em Medicina em todos os níveis. O mesmo é professor titular da UFRGS, atuando no curso de Medicina. O outro líder do grupo, também com formação em Medicina, não é docente, mas médico contratado do Hospital de Clínicas de Porto Alegre (HCPA). Durante seu período de atuação, o grupo manteve interaçôes com um hospital universitário nas áreas de pesquisa científica e treinamento do pessoal. Suas linhas de pesquisa são cirurgia bariátrica - obesidade, cirurgia metabólica, cirurgia videolaparoscópica, defeitos da parede abdominal e oncologia cirúrgica. Em 2008, o grupo era formado por cinco participantes, contando com três pesquisadores e dois estudantes. Em 2015, contava com três pesquisadores e três estudantes. As interaçóes desse grupo foram classificadas como: pesquisa científica sem consideraçóes de uso imediato dos resultados; pesquisa científica com consideraçôes de uso imediato dos resultados; e treinamento de pessoal do parceiro pelo grupo, incluindo cursos e treinamento "em serviço".

Diferente dos grupos citados anteriormente, o grupo D náo se enquadra nas Ciências da Saúde, mas sim nas Ciências Biológicas / Farmacologia. Foi formado

4 Esse pesquisador é também o líder de outro grupo, o qual foi inicialmente identificado via o trabalho de Tatsch, Ruffoni e Botelho (2016). Tal grupo, cujas linhas de pesquisa englobam a neuromecânica do movimento humano, a plasticidade neuromuscular e a reabilitaçấo em traumato-ortopedia, foi formado em 2000. Pertence à área das Ciências da Saúde / Educaçáo Física. Suas interaçōes ocorriam não apenas com empresas privadas, mas também com um hospital e uma instituiçấo de educação superior. Essas parcerias incluíram pesquisa científica, treinamento de pessoal e atividades de engenheira não rotineiras, todas sem transferência de recursos, envolvendo exclusivamente relacionamento de risco. Em termos de recursos humanos, o grupo apresentou um crescimento considerável: em 2000 eram 11 colaboradores e, em 2016, 47.

5 Ressalta-se que o líder entrevistado optou por explanar mais a respeito da pesquisa que está sendo desenvolvida no momento por este grupo B e menos sobre as pesquisas daquele grupo primeiramente identificado, conforme nota de rodapé 4 . De acordo com ele, esse grupo, cujo objeto são tecnologias assistidas, está mais ativo atualmente, merecendo mais atenção. No entanto, no relato das suas experiências, também comentou situaçôes e vivências experienciadas a partir daquele primeiro grupo identificado, as quais foram também incorporadas neste texto. 
em 2006 sob a liderança de professor graduado em Biologia e pós-graduado em Bioquímica, com foco na neurociência. Entre 2006 e 2010, o grupo realizou pesquisas nas linhas de farmacologia. Neste mesmo período, a única interaçáo reportada foi com uma empresa atuante no setor de pesquisa e desenvolvimento científico. Atualmente, realiza pesquisas nas linhas de biologia e farmacologia de tumores neurais embrionários, biologia molecular da memória, genômica de receptores do sistema imune e sinalização por neurotrofinas e neuropeptídeos em câncer. Em 2016, o grupo contava com oito pesquisadores e 13 estudantes, totalizando 21 colaboradores. No presente, engloba em torno de 30 participantes. Ainda em 2016, as interaçóes realizadas eram exclusivamente com hospitais na pesquisa científica, envolvendo transferência de recursos financeiros e insumos materiais e fornecimento de bolsas. Além de expressiva produção intelectual, o grupo possui quatro patentes depositadas.

O grupo E foi criado em 1997 sob a liderança de professor com títulos de graduação e mestrado em Medicina. Atualmente, há também outra pesquisadora líder com a mesma formação. São realizadas pesquisas na linha de fisiopatologia e clínica do transtorno bipolar. Em 2006, primeiro ano de registro do grupo no Censo do Diretório do CNPq, contava com 19 participantes: 16 pesquisadores e três estudantes. A partir de 2010, o grupo passou a ser liderado também por professora formada em Medicina com doutorado em bioquímica. Em 2016, contava com 23 colaboradores, dos quais 11 eram pesquisadores e 12 estudantes.

A partir desta descrição e da análise das informaçóes provenientes das entrevistas realizadas foi possível identificar elementos relevantes que caracterizam a operação, a interação e a geração de conhecimento e inovação dos grupos investigados, tal como está apresentado a seguir.

A multidisciplinaridade é uma característica da maioria dos grupos investigados (A, B, D e E); apenas o $\mathrm{C}$ é composto por pesquisadores exclusivamente médicos. No caso do grupo A, participam professores da psiquiatria, da genética, do departamento de biologia e genética molecular e da educação. No grupo B estão envolvidos educadores físicos, fisioterapeutas e engenheiros. Já no grupo D participam biólogos, médicos, biomédicos, farmacêuticos e biotecnólogo. No grupo E colaboram médicos, farmacêuticos, biomédicos, fisioterapeuta, educador físico, jornalista e profissionais formados em letras.

A respeito das interaçóes/parcerias com os hospitais, observa-se que essas são as mais destacadas pelos grupos consultados. Este tipo de parceria acontece especialmente com o HCPA, justamente o hospital-escola da UFRGS, que é a universidade onde os docentes/pesquisadores, líderes dos grupos, estão vinculados. Todos os cinco 
líderes entrevistados deram especial ênfase à interação com o HCPA. Um dos líderes chegou a dizer que sem o hospital o grupo não existiria.

O HCPA foi fundado em 1970 como uma empresa pública de direito privado, contando com patrimônio próprio e autonomia administrativa. O hospital promove atividades práticas de ensino para um conjunto de cursos da UFRGS - Medicina, Enfermagem, Biomedicina, Ciências Biológicas, Educação Física, Farmácia, Nutrição, Odontologia, Pedagogia e Psicologia -; além de ofertar em torno de 50 programas de residência médica, em 25 áreas de atuação. Possui um Centro de Pesquisa Experimental com seis laboratórios multiusuários e 20 laboratórios temáticos e oferece infraestrutura para a realização de todas as etapas de estudos clínicos e epidemiológicos.

Com capacidade instalada de mais ou menos 900 leitos (contando os da Unidade de Tratamento Intensivo - UTI), sendo mais de $85 \%$ destinados a pacientes do Sistema Único de Saúde (SUS), o HCPA é um hospital de alta complexidade e referência nacional. Além dos leitos, a estrutura de atendimento do Clínicas conta ainda com 40 salas de cirurgia, 146 salas para atendimento ambulatorial e 13 de emergência. No momento, novos prédios estáo sendo construídos, o que deve ampliar em quase $70 \%$ a área atual. Possui mais de 6 mil colaboradores. Destaca-se ainda que o HCPA é referência em gestão, desempenhando papel relevante no âmbito do Programa Nacional de Recuperação dos Hospitais Universitários (REHUF) do Ministério da Educação.

Segundo os entrevistados dos grupos A, C, D e E, uma das razóes que torna interessante a atuação em tempo quase integral no hospital está relacionada às especificidades da institucionalidade do HCPA, que possui autonomia financeira e administrativa em relação à Universidade. Isso dá agilidade à tramitação de processos, facilita o estabelecimento de convênios e a captação de recursos. Dois líderes de grupos da área das Ciências da Saúde / Medicina, mais o das Ciências Biológicas / Farmacologia, possuem inclusive seus gabinetes de trabalho no hospital. A líder do grupo E acrescenta que o HCPA é gerenciado de forma muito eficiente, o que auxilia os investigadores a se focarem nas pesquisas, não tendo que se preocupar em demasia com burocracias.

O grupo A atua no HCPA por meio de laboratório de atendimento a pacientes com TDAH do SUS, além de interagir também com outros hospitais-escola: da Universidade de Sáo Paulo (USP), da Universidade Federal do Rio de Janeiro (UFRJ) e de Pelotas (UFPel) no RS. 
No grupo B, a interaçáo com o HCPA se deu, inicialmente, na área de engenharia biomédica do hospital, a partir de suporte técnico fornecido por engenheiro do hospital para a manutençáo de equipamentos do grupo de pesquisa. Segundo o líder, havia capacitação dos profissionais da área de engenharia biomédica do HCPA, pois "tinham o know-how para abrir um equipamento importado, ver qual era o problema e identificar soluçóes”. Mostravam-se, assim, capazes de realizar engenharia reversa. De acordo com o entrevistado, há neste setor do hospital importante expertise para construção de equipamentos. $\mathrm{Na}$ fase atual da pesquisa, os engenheiros biomédicos do hospital continuam tendo papel-chave, via construção de protótipos, mas a interação com o HCPA ampliou-se. Agora visa também uma interação com os usuários. Isso deverá ser feito pela participação de pacientes da UTI na testagem do equipamento. Primeiro farão parte do estudo pacientes do HCPA e, adiante, pacientes de UTIs de outros hospitais-escola - Complexo da Santa Casa, Instituto de Cardiologia e Hospital São Lucas - serão também incorporados à testagem.

No HCPA, pesquisadores e médicos do grupo $\mathrm{C}$ atuam no serviço de cirurgia do aparelho digestivo, atendendo pacientes do SUS. Tal serviço realiza diagnóstico ambulatorial e análise de exames e, principalmente, trata estes pacientes com procedimentos cirúrgicos de alta complexidade. Realizam cirurgias bariátrica e defeitos da parede abdominal. Além de atuarem nesse serviço, os pesquisadores do grupo também participam do laboratório de pesquisa experimental no campo da cirurgia do HCPA (infraestrutura compartilhada por equipes de cirurgiôes de várias especialidades).

Já o grupo D coordena laboratório experimental temático (relacionado a tumores cancerígenos e à neurobiologia) no HCPA. O líder esclarece que o grupo possui forte apoio do Instituto do Câncer Infantil, entidade privada sem fins lucrativos, localizada dentro HCPA, que atua há 25 anos. O Instituto é apoiado integralmente por doação da comunidade privada, de empresas ou de pessoas, com ou sem isenção fiscal. Segundo o entrevistado, o serviço oferecido pelo Instituto é de excelência, alcançando a cura de $70 \%$ das crianças atendidas (essa média no RS gira em torno de 40\%). A partir de determinado período, o Instituto tomou a decisão de investir em pesquisa biológica e passou a apoiar o grupo que se voltou à pesquisa do câncer infantil, da biologia do câncer infantil, visando descobrir novas alternativas de tratamento.

O grupo E atende pacientes do SUS via ambulatório, coordena laboratório experimental temático voltado à pesquisa sobre bipolaridade (onde se dáo os estudos de bancada) e realiza ensaios clínicos junto ao Centro de Pesquisa Clínica do Hospital. 
Os líderes sublinharam ainda a importância do HCPA como espaço de aprendizagem e capacitação. De acordo com todos os entrevistados, o HCPA possui relevante papel no sistema educacional do RS no campo das ciências da saúde. Ali são capacitados alunos de graduação e pós-graduação, bem como residentes de várias especialidades. São também treinados profissionais da saúde de distintas áreas.

Ainda no que tange à interação com os pacientes, como relatado, tal interação ocorre com pacientes atendidos nos ambulatórios do próprio HCPA, via SUS, mas também por meio de ensaios clínicos e epidemiológicos realizados nesse hospital, mas não só. O grupo $\mathrm{A}$, por exemplo, a partir de parceria com pesquisadores da UFPel, realiza pesquisa epidemiológica (estudos de coorte) junto à população do município de Pelotas. Ainda para estudos de coorte, esse grupo conta também com parcerias internacionais, visando coleta junto a pacientes de outras localidades. Já o grupo C, por meio de pesquisadores parceiros da Universidade Federal do Rio Grande (FURG), via seu respectivo hospital-escola, acessa dados de pacientes ali tratados.

A interação com outros pesquisadores foi identificada pelos grupos como muito importante para a construçáo do conhecimento gerado. A relaçáo de parceria com outros pesquisadores e grupos ganha especial destaque dos líderes entrevistados. Foi ressaltado o quâo relevante é a troca de informaçóes e conhecimentos entre grupos de referência, não só no Brasil, mas também no exterior. Buscar interagir com instituições e pesquisadores internacionais que trabalham na fronteira é, sem dúvida, conforme os líderes, uma oportunidade de se avançar nas investigaçóes e na geração de conhecimentos científicos.

A importância dessas parcerias foi enfatizada pelos líderes dos grupos D e E ao comentarem a criação do Instituto Nacional de Ciência e Tecnologia Translacional em Medicina (INCT-TM) que reúne diversos pesquisadores de várias universidades brasileiras que cooperam entre si e com outros pesquisadores nacionais e internacionais. O INCT-TM foi criado em 2009. As instituiçôes participantes são: UFRGS (sede inicial), UFRJ, USP - Ribeirão Preto (sede atual), Pontifícia Universidade Católica do Rio Grande do Sul (PUCRS) e Universidade do Extremo Sul de Santa Catarina (Unesc).

Em relação às interaçôes/parcerias com a induistria manufatureira, seja de fármacos, equipamentos médicos, ou de outros segmentos, observou-se que, embora aconteçam, são as menos frequentes.

Dentre os cinco grupos investigados, a interação com a indústria manufatureira se dá com regularidade apenas no grupo A. Neste caso, parcerias com empresas privadas, especialmente da indústria farmacêutica, geralmente ocorrem quando essas 
têm algum interesse em aspectos do tratamento de TDAH, sejam eles medicamentosos ou náo. Todas elas são multinacionais atuando no Brasil, cujo capital tem origem em países como Bélgica, Suíça, Inglaterra e EUA. Para o estabelecimento da parceria, a iniciativa é sempre do grupo. As parcerias ocorrem basicamente com quatro farmacêuticas já há bastante tempo. A interação normalmente se dá com seus departamentos de neurociências.

Segundo o entrevistado, a interação com essas firmas não é do tipo em que a indústria contrata o serviço para conduzir um clinical trial, isto é, um ensaio clínico visando aprovar uma medicaçáo em órgãos reguladores, como a Agência Nacional de Vigilância Sanitária (Anvisa) no Brasil e a Food and Drug Administration (FDA) nos Estados Unidos. Nas palavras do líder, o grupo não trabalha como "prestador de serviço" à indústria. Ele esclarece que o grupo trabalha com um "protocolo de investigaçẫo independente", em que as hipóteses são gestadas pelo grupo. Em outras palavras, a hipótese pode envolver uma molécula da empresa, mas é formulada pelo grupo; o projeto é concebido pelos pesquisadores e os resultados são do grupo. Ainda conforme o líder, as firmas apoiam tal formato porque os resultados podem ser interessantes para elas também. Em suas palavras, "nossa ideia é gerar hipótese a ser testada cientificamente e buscar as parcerias que são necessárias para fazer isso".

A título de exemplo, o líder comentou a seguinte situação: o grupo constrói uma hipótese sobre a responsabilidade de determinado gene na regulação de resposta à medicação. Em função disso, um protocolo é elaborado definindo o número de pacientes que receberão a medicação durante o estudo, buscando avaliar a performance desse gene. Aí entram as empresas, que podem ou doar o medicamento durante a pesquisa ou fornecer recursos para sua compra.

$\mathrm{Na}$ maior parte das vezes, o apoio vem enquanto financiamento para o grupo, de duas formas: ou via apoio para pesquisa ou como verba educacional. Neste último caso, trata-se do que foi denominado de "unrestricted grant", ou seja, a verba é fornecida pela iniciativa privada sem sua participação na determinação do conteúdo educacional. O líder citou como exemplo um projeto para promover educação sobre déficit de atenção e hiperatividade em escolas públicas, em conjunto com a Secretaria Estadual de Educação. A verba fornecida por empresa viabilizou o projeto. Outro exemplo seria a capacitação de docentes, a partir de um programa também proposto pelo grupo e não pela indústria. Nesse caso, o interesse das empresas é ampliar a conscientização do mercado sobre o transtorno.

No caso dos projetos de pesquisa conjuntos com a indústria, o interesse das empresas está na associação da sua imagem a um grupo reconhecido internacio- 
nalmente como gerador de conhecimento no campo da pesquisa da TDAH. Para ilustrar, o líder mencionou ainda um projeto que examinou a prevalência de déficit de atenção em motoboys. Neste projeto, houve também uma parceria com uma empresa do setor automobilístico, que forneceu simuladores de direção de motos. Utilizaram-se dois grupos para testagem, um recebendo medicação e outro placebo, visando analisar se a medicação melhora a performance do condutor. $\mathrm{Na}$ visão do entrevistado, a empresa parceira, que forneceu o medicamento, vislumbra um espaço de mercado a ser conquistado. De acordo com o líder, o resultado do projeto pode originar programa governamental para utilização de medicação, o que, em consequência, impacta na demanda por fármacos.

O grupo E também relatou interação com empresas multinacionais produtoras de fármacos tanto para ensaios clínicos iniciados pelos pesquisadores quanto propostos pela indústria. Neste último caso, a interação se dá a partir de um ensaio clínico que segue protocolos predefinidos. Nesses estudos, a empresa define o protocolo que determina quais indivíduos podem participar do trial, quais medicamentos e dosagens serão utilizados, além do tempo de duração do estudo. Para a líder do grupo, essa situação, na qual o grupo é prestador de serviços, se configura como uma oportunidade de captar recursos aplicáveis em itens que as agências tradicionais não financiam, como manter uma equipe administrativa eficiente para apoiar a gestấo do grupo.

Ainda no que tange ao grupo A, os pesquisadores desenvolveram um aplicativo em conjunto com empresas privadas de diferentes segmentos: farmacêutica multinacional com filial no Brasil, especializada em biofármacos (que financiou o projeto); empresa paulista de serviços em tecnologias de informação, desenvolvedora do software; empresa nacional de consultoria em gestão do tempo; e multinacional britânica que auxilia no fornecimento do conteúdo. $\mathrm{O}$ app, que pode ser baixado de forma gratuita, possui várias funcionalidades: oferece conteúdo sobre TDAH, monitoramento de tratamento, avaliação de sintomas, dentre outras. $\mathrm{O}$ aplicativo registra as informaçóes do paciente na forma de um histórico, criando um dashboard, painel de indicadores com informaçóes consolidadas e disponibilizadas em uma tela para fácil acompanhamento, auxiliando o médico no tratamento dos pacientes. $\mathrm{O}$ grupo entende que a utilização do app pelos pacientes permitirá a coleta de dados úteis para pesquisas futuras. Os direitos autorais (propriedade intelectual) do aplicativo foram registrados.

Já os líderes dos grupos $\mathrm{C}$ e $\mathrm{D}$ informaram não interagir com empresas privadas industrias no presente. O líder do grupo C comentou que tem dificuldade de dedicar 
tempo à prospecção de parceiros. Soma-se a isso o fato de parcerias desta natureza ainda serem malvistas pela comunidade médica científica. Nas suas palavras, "há preconceito" dado que muitas vezes as big pharmas impóem condiçóes que tiram a liberdade dos pesquisadores. De toda forma, ele relata que no passado tiveram uma experiência bem-sucedida de parceria com empresa fabricante de material a ser utilizado em cirurgias de tratamento de obesidade. Esta empresa de capital nacional buscava validar a eficácia de um produto (um baláo intragástrico) junto à Anvisa e, para tanto, precisava testá-lo. Houve a colaboraçáo do grupo nesta etapa, testando em pacientes operados no HCPA e também em hospital privado. A partir daí o produto passou a ser adotado rotineiramente nas cirurgias. Depois desta experiência, o grupo $\mathrm{C}$ não estabeleceu mais interação com empresas industriais.

O líder do grupo $\mathrm{D}$ informou que nunca interagiram com laboratórios farmacêuticos. Ele esclarece que, dadas as características da pesquisa que desenvolvem, há ainda um longo trajeto para que se tenha resultados que possam ser aplicados pela indústria. Segundo ele, o grupo está ainda em uma etapa de pesquisa básica ("estudos de bancada"), "de descoberta, buscando desenvolver estratégias melhores de fármacos experimentais novos". Em compensação, o grupo já deu origem a duas startups, podendo ser consideras spin-offs. Ambas foram incubadas na UFRGS. Uma delas já foi encerrada e a segunda encontra-se atualmente incubada na USP. Essa última tem pelo menos três depósitos de patentes e está em fase de testagem de protótipo.

Já o líder do grupo B comentou que, no passado, contatou empresas privadas nacionais com o intuito de produzir em escala protótipos já testados, mas não obteve sucesso nas negociaçóes. De acordo com ele, não há geralmente uma convergência entre os interesses das firmas privadas e das universidades / grupos de pesquisa. Além disso, acredita que as empresas nacionais têm pouco capital para investimento em P\&D e certa aversão ao risco.

Por fim, referente ao financiamento, destaca-se que, na visão de todos os entrevistados, as agências federais de fomento à pesquisa científica e tecnológica, como o CNPq e a Coordenação de Aperfeiçoamento de Pessoal de Nível Superior (Capes), assim como as agências estaduais como a Fundaçáo de Amparo à Pesquisa do Estado do Rio Grande do Sul (FAPERGS) e a Fundação de Amparo à Pesquisa do Estado de São Paulo (Fapesp), são importantes órgão de financiamento. Todos os pesquisadores líderes se valem de bolsas produtividade do CNPq, bem como participam de editais.

No entanto, os líderes ressaltam que a burocracia para pleitear recursos e prestar contas, assim como o engessamento das rubricas e dificuldades para importação 
de equipamentos e materiais, impóe gargalos e restrições que prejudicam o bom andamento das pesquisas.

O líder do grupo A comentou que, para fugir do engessamento das agências de fomento, eles procuram usufruir das parcerias com as empresas para ter acesso a recursos que são mais flexíveis e que permitem uma maior agilidade na sua utilização. Ele classificou tais recursos de "soft money". Segundo ele, o montante não é tão expressivo, mas viabiliza viagens, participação em eventos e outras atividades consideradas relevantes para a construçâo e transferência de conhecimento científico.

Já a líder do grupo E acrescentou que eles adotam a estratégia de buscar recursos em agências internacionais visando acesso a montantes mais significativos e à flexibilidade de seu uso. Tais recursos, por exemplo, auxiliam na contratação de pessoas que participam da equipe, o que facilita a criação de uma estrutura de pessoal perene.

No caso do grupo $\mathrm{D}$, o financiamento de suas pesquisas advém tanto destes recursos das agências públicas e do próprio fundo para pesquisa do HCPA, quanto de doaçốes realizadas pela comunidade ao Instituto do Câncer Infantil e canalizadas para o laboratório experimental.

Esse fundo do próprio HCPA financia projetos de pesquisa de colaboradores do hospital. A seleção se dá baseada em uma série de critérios que privilegiam a meritocracia. Os líderes comentaram ainda sobre a eficiência do hospital na gestão de recursos, sejam advindos do fundo ou provenientes de órgáos externos e administrados na fundação médica do HCPA.

Considerando o problema de pesquisa descrito inicialmente no trabalho, apresentam-se, a seguir, algumas reflexóes.

Como aponta a literatura, as variadas formaçóes das equipes dos grupos de pesquisa apresentam-se como requisito importante para o processo de desenvolvimento científico e tecnológico na área. Observaram-se tanto a participação de diferentes atores institucionais quanto a multidisciplinaridade na formação das equipes.

Quanto à ampla gama de organizaçóes envolvidas, a literatura destaca o papel dos hospitais universitários. Nesta direçấo, Thune e Mina (2016) indicam que hospitais com um foco forte em aprendizado possuem performances inovativas mais relevantes. Tal questão é reforçada nos resultados desta pesquisa, já que foi atribuído ao HCPA, hospital-escola da UFRGS, relevante papel enquanto espaço de interação e pesquisa para a geraçáo de conhecimento e inovação. Como consequência, o hospital se beneficia dos resultados e achados das pesquisas, via um aprimoramento em seus serviços. 
A importância do HCPA, como locus de investigação e experimentação, se dá em razão tanto de os laboratórios de pesquisa experimental e clínica, onde os grupos atuam, estarem localizados no próprio HCPA, quanto do fato de o hospital oportunizar o contato dos pesquisadores com profissionais de diferentes áreas, bem como com pacientes. Essa realidade se aplica aos cinco grupos investigados; maiormente aos casos dos grupos A, C, D e E, mas também ao B, que, embora não tenha seu laboratório localizado no $\mathrm{HCPA}$, se vale dos pacientes lá internados para a testagem dos seus equipamentos.

A partir da análise do modus operandi do grupo C, identificou-se que a prática experimental pode levar à geração de novas ideias em termos tanto de técnicas e serviços existentes quanto de técnicas e serviços novos. Também o grupo $\mathrm{D}$, quando de seus estudos mais voltados à clínica, já gerou novos procedimentos no tratamento de pacientes infantis com câncer. $\mathrm{O}$ grupo $\mathrm{E}$ frisou a relevância do contato com pacientes a partir dos atendimentos via ambulatório e das pesquisas clínicas, para a geraçẫo de conhecimentos que revertem em avanços no tratamento. Tais achados reforçam ideias presentes na literatura, como, por exemplo, em Thune e Mina (2016) e Nelson et al. (2011), que salientam que os hospitais são fontes de novas ideias e canais para inovaçóes geradas em outros pontos do sistema de inovação em saúde. Por isso, a análise das suas contribuiçôes deve ser compreendida em termos relacionais e coevolucionários. Consoli e Mina (2009) enfatizam que os hospitais são o local da prática clínica, sendo o maior canal para a revelação do potencial e das desvantagens de novos tratamentos.

Outra característica identificada foi a relevância da interação com pacientes para todos os grupos. Tal importância está relacionada ou ao fato de os pacientes participarem de etapas de testagem das pesquisas, fornecerem insumos biológicos para o desenvolvimento de pesquisas, ou pelo seu atendimento permitir que hipóteses de pesquisa sejam construídas. Verificou-se, em síntese, que o feedback da interação com esses usuários afeta a direção dos esforços de pesquisa e inovação. Muitas vezes, esse acesso aos pacientes se dá via o próprio HCPA, mas não só. Novamente, tal resultado vai ao encontro dos achados de outros autores, como Gelijns e Rosenberg (1994), que descrevem a inovação nas ciências da saúde como um processo dinâmico influenciado pela interação entre os desenvolvedores e os usuários. Nessa direção, estâo ainda os trabalhos de Consoli e Mina (2008), Nelson et al. (2011) e Thune e Mina (2016), que também salientam o papel dos pacientes como participantes do processo de inovação médica. 
Outra característica que emergiu da pesquisa foi a escassez de parcerias com a indústria. Tal situação foi normalmente atribuída ou às características/fase em que a pesquisa se encontra (quando considerada básica, está ainda numa etapa bastante anterior a uma possível interação), ou à dificuldade de conciliar os interesses dos grupos e das empresas. A burocracia da universidade também foi citada como um impeditivo, assim como a falta de capacidade de financiamento da indústria nacional. Soma-se a isso o fato de os laboratórios de P\&D das multinacionais estarem geralmente situados junto às suas matrizes, impondo uma distância geográfica e também cultural que dificulta a interação.

Tal desconexão entre aqueles que geram o conhecimento nas universidades e a indústria é apontada pela literatura que analisa a realidade de países em desenvolvimento. Nesse sentido, Chaves e Albuquerque (2006) concluem que há uma desconexão entre a produção científica e tecnológica no sistema de inovação do setor saúde no país. A pesquisa realizada corrobora essa conclusão, já que os grupos analisados têm elevada produção científica e baixíssima interação com a indústria, conformando um sistema inovativo imaturo, típico de países emergentes (ALBUQUERQUE, 1996, 2009; BOTELHO; TATSCH, 2015).

Em outras palavras, podemos dizer que, diferentemente do que ocorre nos países desenvolvidos, onde as inovaçôes na area médica "are increasingly dependent on the interaction between the clinical delivery of health care services and a manufacturing system that develops and delivers new drugs and new instrumentation and devices to enhance the delivery of clinical services" (METCALFE; JAMES; MINA, 2005, p. 1301), nos países emergentes, como o Brasil, esse encadeamento náo acontece ainda de forma plena.

\section{Considerações finais}

A presente pesquisa teve como objeto as interaçóes estabelecidas por cinco grupos de pesquisa da área da saúde pertencentes à UFRGS. O estudo exploratório realizado permitiu identificar importantes características das interaçóes que se estabelecem entre os atores envolvidos, objetivando avanços na assistência médica e o desenvolvimento de inovaçóes. Tais características são:

- equipes multidisciplinares de pesquisadores;

- hospital-escola é ator-chave; 
- pacientes são atores relevantes no estabelecimento de interaçôes e construção de conhecimento pelos grupos, sendo a pesquisa clínica e a assistência caminhos importantes para a geraçáo de novas ideias;

- outros pesquisadores de centros de pesquisa ou universidades do Brasil e do exterior participam do processo de geração de conhecimento;

- firmas industrias têm pouca ou nenhuma presença nas interaçóes estabelecidas;

- há uma desconexão entre produção científica e tecnológica, visto que os grupos investigados possuem elevada produção científica e baixíssima interação com a indústria manufatureira.

Releva reforçar que foram claramente identificados, no presente estudo, os três caminhos mencionados por Nelson et al. (2011), os quais moldam a direção e a velocidade das inovaçóes na prática médica: os avanços científicos, responsáveis pelo maior entendimento do corpo humano e das patologias das doenças; os avanços nas capabilities tecnológicas, que permitem o desenvolvimento de novas modalidades de diagnóstico médico e tratamento; e o learn by doing, via aprendizado na prática clínica, que possibilita progressos em diagnósticos e tratamentos.

Em relação às especificidades de países emergentes, os resultados do estudo conversam bem com a literatura a respeito da interação universidade-empresa no Brasil. Vários trabalhos apontam para o fato de estas relaçôes serem ainda escassas no cenário de ciência e tecnologia do país. Há que se construir, ao longo do tempo, uma institucionalidade, em sentido largo, para promover aproximaçóes entre esses diferentes atores do sistema de inovaçấo. Significa, nos termos de Hanlin e Andersen (2016), ampliar os fluxos para a troca de conhecimento, de modo a articular os atores e instituiçôes em prol do aprimoramento dos sistemas de saúde e bem-estar. Para esse fim, não bastam apenas soluçóes tecnológicas. Novas articulações entre atores devem emergir para que se tenham ações com foco na diminuição das desigualdades globais em termos de saúde e bem-estar, tal como discutido também por Cassiolato e Soares (2015), tendo como referência a discussão mais ampla de desenvolvimento econômico.

Outra importante conclusão em termos de implicaçôes para políticas públicas diz respeito às oportunidades de melhor aproveitar os conhecimentos gerados pelo setor científico brasileiro, incentivando a indústria nacional a valer-se de oportunidades que se abrem a partir das pesquisas realizadas por grupos atuantes nas universidades 
do nosso país. Soma-se a isso a necessidade de promover açóes de política que incentivem a criação de startups a partir das descobertas científicas nas universidades. Esse parece ser um caminho a ser trilhado com maior ênfase.

Por fim, vale sublinhar que a literatura internacional destaca, em especial, as interaçóes universidade-empresa e assistência-indústria como chaves para o progresso científico-tecnológico no campo da saúde. Em contrapartida, nossos resultados demonstraram que, no caso brasileiro, tais interaçóes são pouco frequentes, ao passo que aquelas entre universidade-assistência possuem papel importante para inovaçôes em tratamentos. Cabe assim avançar na construção de um referencial que explore as peculiaridades dos países emergentes.

\section{Referências bibliográficas}

ALBUQUERQUE, E. M. Sistema Nacional de Inovação no Brasil: uma análise introdutória a partir de dados disponíveis sobre a ciência e a tecnologia. Revista de Economia Política, v. 16, n. 3, p. 56-72, 1996.

- Catching up no século XXI: construção combinada de sistemas de inovação e de bem-estar social. In: SICSÚ, J.; MIRANDA, P. (org.). Crescimento econômico: estratégias e instituições. Rio de Janeiro: Ipea, 2009. p. 55-83.

ALBUQUERQUE, E. da M.; CASSIOLATO, J. E. As especificidades do Sistema de Inovação do Setor Saúde. Revista de Economia Política, v. 22, n. 4 (88), outubro-dezembro 2002.

ASHEIM, B.; GERTLER, M. S. The geography of innovation: regional innovation systems. The Oxford handbook of innovation. Oxford: Oxford University Press, 2006.

BOTELHO, M.; TATSCH, A. L. Health services and innovation in Brazil: an analysis based on teaching and research hospitals in Rio Grande do Sul and Minas Gerais. In: CASSIOLATO, J. E.; SOARES, M. C. (ed.). Health systems, equity and development. Rio de Janeiro: E-papers, 2015. p. 355-381.

CASSIOLATO, J. E.; SOARES, M. C. Health systems, development and health - an introduction. In: CASSIOLATO, J. E.; SOARES, M. C. (ed.). Health systems, equity and development. Rio de Janeiro: E-papers, 2015. p. 15-57.

CHAVES, C. V.; ALBUQUERQUE, E. M. Desconexão no sistema de inovação do setor saúde: uma avaliação preliminar do caso brasileiro a partir de estatísticas de patentes e artigos. Economia Aplicada, v. 10, n. 4, p. 523-539, 2006.

CONSOLI, D.; MINA, A. An evolutionary perspective on health innovation systems. Journal of Evolutionary Economics, v. 19, n. 2, p. 297-319, 2009. 
COOKE, P. Introduction: origins of the concept. In: BRACZYK, H.-J.; COOKE, P.; HEIDENREICH, M. (ed.). Regional innovation systems. London: UCL Press, 1998. p. 2-25.

COSTA, A. B. da; RUFFONI, J.; PUFFAL, D. Proximidade geográfica e interação universidade-empresa no Rio Grande do Sul. Revista de Economia, v. 37, n. especial, p. 213-238, 2011.

DJELLAL, F.; GALLOUJ, F. Mapping innovation dynamics in hospitals. Research Policy, v. 34, n. 6, p. 817-835, 2005.

FREEMAN, C. The 'National System of Innovation' in Historical Perspective. Cambridge Journal of Economics, n. 19, p. 5-24, 1995.

GELIJNS, A.; ROSENBERG, N. The dynamics of technological change in medicine. Health Affairs, v. 13, n. 3, p. 28-46, 1994.

HANLIN, R.; ANDERSEN, M. H. Health systems strengthening. Rethinking the role of innovation. Globelics Thematic Report 2016. Denmark: Aalborg University Press, 2016.

HICKS D.; KATZ, J. S. Hospitals: the hidden research system. Science and Public Policy, v. 23, n. 5, p. 297-304, 1996.

LUNDVALL, B-Å. Innovation as an interactive process: from user-producer interaction to the national system of innovation. In: DOSI, G. et al. (ed.). Technical change and economic theory. Londres: Pinter, 1988. p. 349-369.

(ed.). National innovation systems: towards a theory of innovation and interactive learning. London: Pinter, 1992.

MALERBA, F. Sectoral system of innovation and production. Research Policy, v. 31, n. 2, p. 247-264, 2002.

METCALFE, J. S.; JAMES, A.; MINA, A. Emergent innovation systems and the delivery of clinical services: the case of intra-ocular lenses. Research Policy, 34, n. 9, p. 1283-1304, 2005.

MOWERY, D. C.; SAMPAT, B. N. Universities in National Innovation Systems. In: FAGERBERG, J.; MOWERY, D. C.; NELSON, R. R. (org.). The Oxford handbook of innovation. Oxford: Oxford University Press, 2006.

NELSON, R. (ed.). National Innovation Systems: a comparative analysis. Nova York: Oxford University, 1993.

NELSON, R. R.; BUTERBAUGHB, K.; PERLB, M.; GELIJNS, A. How medical know-how progresses. Research Policy, v. 40, n. 10, p. 1339-1344, 2011.

NELSON, R. R.; WINTER, S. G. An evolutionary theory of economic change. Cambridge, Mass./London: The Belknap Press of Harvard University Press, 1982. 
SILVA NETO, F. C. C. et al. Abordando os grupos de pesquisa sobre sua relação com as instituiçôes: uma avaliação por área específica de conhecimento. In: XV SEMINÁRIO SOBRE A ECONOMIA MINEIRA. Anais [...]. Diamantina: Cedeplar / UFMG, 2012.

TATSCH, A. L.; RUFFONI, J.; BOTELHO, M. R. A. Sistema de innovación de la salud: redes en Rio Grande do Sul/Brasil. América Latina Hoy, v. 73, p. 87, 2016.

THUNE, T.; MINA, A. Hospitals as innovators in the health-care system: a literature review and research agenda. Research Policy, v. 45, n. 8, p.1545-1557, Oct. 2016.

WINDRUM, P.; GARCÍA-GONII, M. A neo-Schumpeterian model of health services innovation. Research Policy, 37, n. 4, p. 649-672, 2008.

\section{(cc) EY-NC}

Esta obra foi licenciada sob uma Licença Creative Commons Atribuição-NãoComercial 3.0 Brasil. 